\title{
Design and Analysis of Braking System of An ATV with Efficient Wheel Locking and Weight Reduction
}

\author{
(Efficient braking in an ATV with wheel locking)
}

\author{
Shreyash Royzada / B.Tech UG Student \\ Mechanical Engineering \\ National Institute of Technology, \\ Raipur, Chhattisgarh
}

\begin{abstract}
Study and implementation of a braking system in an ATV. Detailed brake calculations and focusing on attaining four wheel locking. Designing of lightweight parts that can withstand all the stresses induced during working. Implementing Inboard braking successfully in the circuit to reduce unsprung mass. Structural analysis of the brake pedal, pedal and master cylinder mounting. Structural analysis of the brake disc to ensure usage under safety limits.
\end{abstract}

Keywords-Inboard braking, Brake disc cooling,, Brake disc design, Brake Pedal Design, Pedal Mount design, Weight reduction.

\section{INTRODUCTION}

The usage of inboard braking systems is a key component which helped us in achieving complete locking of the four wheels. The technology has been used in a variety of automobiles but isn't very common among everyday vehicles. In an Inboard braking system a common disc is installed, this disc is directly attached to the wheel axle connecting the two wheels. Thus it is mostly used on the driving axle. This usage of a single disc puts more stresses on the disc as this one disc now stops two rotating wheels. An efficient and strong inboard brake disc is very necessary to implement this circuit. The presence of higher stresses results in high heating of the inboard brake disc. This was resolved by designing a disc with efficient air flow while also keeping the strength necessary.

A braking system works by converting the kinetic energy of the vehicle into heat energy. Therefore it is very crucial that this dissipation of heat is done in a more efficient way thus increasing performance. As we'll see further the rear brake disc will experience higher forces than it requires for stopping.

\section{A.. $\quad$ Brake Circuit}

The Brake Circuit consisted of the Master Cylinder, Stainless Steel braided Brake lines and the calipers. The Master cylinder was chosen considering the respective brake calculations and the requirements of the vehicle. Stainless steel braided brake lines were chosen to minimize pressure loss throughout the circuit as they ensure no sharp bends in the brake line. The calipers were chosen with respect to the brake calculations..

\section{B. Brake Pedal}

The Brake Pedal was designed from scratch integrating technologies for minimizing weight and maximizing strength. Two thin Separate steel plates were used, they were joined using hollow cylindrical tubes to give the plates torsional strength. The use of thin plates instead of one big thick one provided with more strength and weight reduction. The design was analysed in ANSYS 19.2 for credibility of strength and was found out to withstand forces 2 times the usual loading. The more comprehensive study for the same is also done in section 3 .

\section{Brake Disc}

The Brake disc was designed to maximize heat flow and incorporated the use of two separate designs. The first design is for the front wheels while the second design is for the rear inboard disc setup. As the rear disc requires higher heat dissipation it is therefore designed keeping this in mind.

\section{THE BRAKE CIRCUIT}

The brake circuit is a pneumatic system that works on the principle of transfer of pressure. The applied force by the driver on the pedal converts into hydraulic pressure which in turn converts the Kinetic energy of the moving vehicle into heat energy dissipated through the Brake discs.

Here we discuss how we decided the values of every part used in the brake circuit. The braking Calculations are done considering some unknown variables while keeping some variables known. We assumed these variables based on the data we had on parts that we were going to use. The following data was known to us while our calculations (TABLE 1)-

TABLE I.

\begin{tabular}{|l|l|c|c|}
\hline \multicolumn{1}{|c|}{ Variable } & Quantity & Symbol & Value \\
\hline $\begin{array}{l}\text { Master Cylinder Bore } \\
\text { Diameter }\end{array}$ & 1.0 & $\mathrm{D}_{\mathrm{mc}}$ & $19.05 \mathrm{~mm}$ \\
& & & \\
Caliper Pot diameter- & & & \\
Front- Fixed, 2 Piston \\
Rear- Fixed, 4 Piston & 1.0 & $\mathrm{D}_{\mathrm{cf}}$ & $30 \mathrm{~mm}$ \\
& & $\mathrm{D}_{\mathrm{cr}}$ & $30 \mathrm{~mm}$ \\
\hline & & & \\
Tyre Radius- & 2.0 & $\mathrm{R}_{\mathrm{f}}$ & $266.7 \mathrm{~mm}$ \\
Front & 2.0 & $\mathrm{R}_{\mathrm{r}}$ & $304.8 \mathrm{~mm}$ \\
Rear & \multicolumn{3}{c}{0.6} \\
\hline
\end{tabular}




\begin{tabular}{|l|c|c|c|}
\hline $\begin{array}{l}\text { Frictional Coefficient } \\
\text { between road and tyres }\end{array}$ & & \\
\hline $\begin{array}{l}\text { Frictional Coefficient } \\
\text { between Pads and brake } \\
\text { disc }\end{array}$ & $\mathrm{U}_{\mathrm{p}}$ & 0.4 \\
\hline $\begin{array}{l}\text { Distance of COM from } \\
\text { Front Axle }\end{array}$ & $\mathrm{C}_{\mathrm{Mxf}}$ & $950 \mathrm{~mm}$ \\
\hline $\begin{array}{l}\text { Distance of COM from } \\
\text { Rear Axle }\end{array}$ & $\mathrm{C}_{\mathrm{Mxr}}$ & $370 \mathrm{~mm}$ \\
\hline $\begin{array}{l}\text { Height of COM wrt to } \\
\text { ground }\end{array}$ & $\mathrm{C}_{\mathrm{My}}$ & $485 \mathrm{~mm}$ \\
\hline Ground Clearance & & & $350 \mathrm{~mm}$ \\
\hline
\end{tabular}

The Unknown data is the data of how much force will the driver apply on the pedal and how much should the pedal leverage be. The target is that the driver should be easily able to brake and for this one can assume that instead of calculating the applied force or the leverage, simply calculate the required amount of pressure in the Master Cylinder for achieving Wheel Locking.

Once the Pressure is calculated one can backtrace it to a balance between the applied force and the mechanical Leverage (Pedal Ratio).

\section{A. Mass Selection-}

Apart from the values used above we also used the mass of the vehicle with a driver which is $270 \mathrm{Kgs}$, keeping a safety factor of 1.5 we choose $400 \mathrm{Kg}$ as our weight carried by the vehicle while doing all our calculations.

\section{B. Brake Disc Selection-}

The Front Brake discs were designed considering the space available in the front rim and an optimal front disc diameter of $140 \mathrm{~mm}$ was chosen in the end.

For the rear setup the disc had to be larger in size such that more surface area is available for heat dissipation. The rear calipers are mounted on the chassis while the disc is mounted on the axle shaft coming from the gearbox. The size was finally chosen to be $190 \mathrm{~mm}$ in diameter. This size was sufficient for heat dissipation as well as our working conditions.

Detailed analysis of both the disc and it's properties are also discussed in the paper in section 5 .

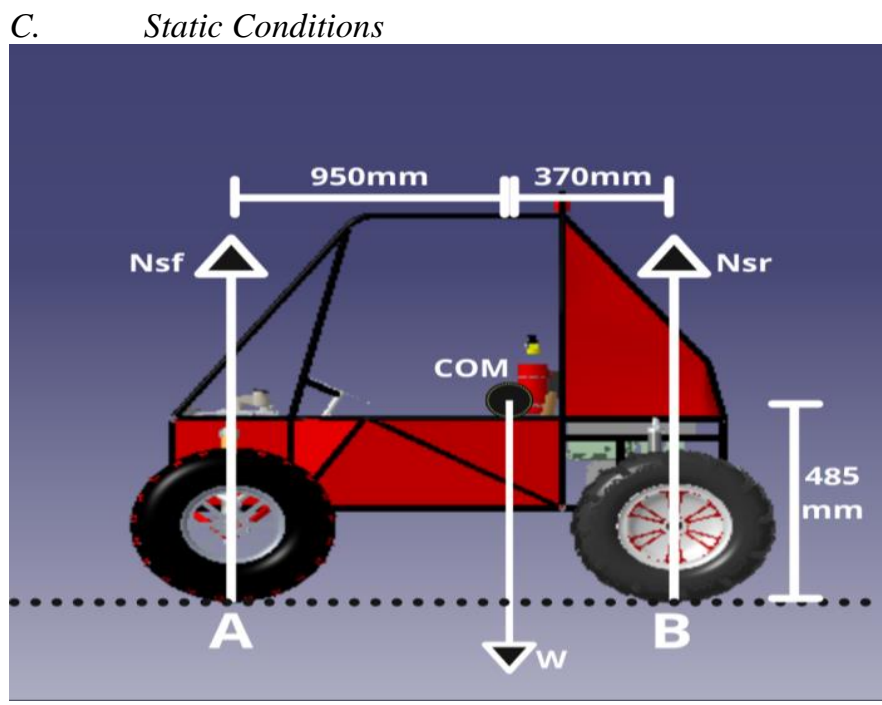

Fig-1: Static FBD (measurements not to scale)
As clearly visible in Fig-1 in static conditions the vehicle will experience a simple weight distribution where Normal reaction forces applied on each axle will balance up the overall weight of the vehicle.

We may Conclude this by writing the following equations-

$$
\begin{array}{cc}
\sum F_{y}=0, \quad \mathrm{~N}_{\mathrm{sf}}+\mathrm{N}_{\mathrm{sr}}=\mathrm{W}=400 * 9.8 \\
\sum M_{a}=0, \quad \mathrm{~W}^{*} 0.950=\mathrm{N}_{\mathrm{sr}} * 1.32 \\
\mathbf{N}_{\mathrm{sr}}=(400 * 9.8 * 0.950) / 1.32
\end{array}
$$

$\mathbf{N}_{\text {sr }}=2821.212 \mathrm{~N}, \mathbf{N}_{\mathrm{sf}}=1098.788 \mathrm{~N}$

\section{A. Achieving Wheel Locking-}

We have obtained the Normal values in static condition. When we apply the brakes the vehicle shall experience a deceleration. This deceleration is a result of friction between the non rotating wheels and the ground. For achieving locking of the wheels our braking system should be capable of providing a balancing torque equal to the torque the wheels experience while being dragged through the road under frictional forces.

This deceleration will cause the body to experience a pseudo force in the forward direction. This force will cause the weight to shift on the forward axle. This is called the weight transfer and the value of weight that gets transfered is calculated ahead.

It is essential to keep note of the values that get changed during deceleration. The Normal reaction in dynamic conditions will be different and this value of Normal must be used while calculating the torque that the wheels must produce to obtain braking effectively. We assume the new Normal reactions to be Ndf and Ndr respectively.

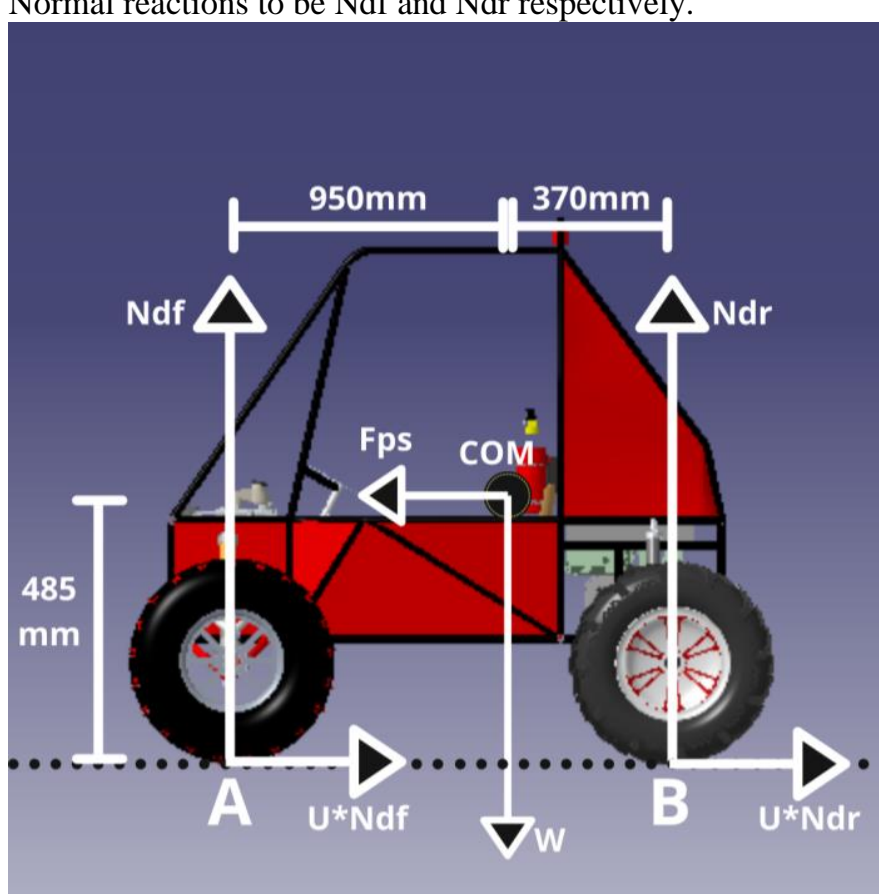

Fig -2: Dynamic FBD(measurements not to scale)

Fig-2 shows the forces acting on the body while it experiences deceleration. Both our wheels are locked in this condition this is only possible when our braking circuit is efficient enough to make sure that the torque applied by our braking system is balancing the torque applied by the Frictional forces $\mathrm{U}^{*} \mathrm{~N}_{\mathrm{df}}$ and $\mathrm{U} * \mathrm{~N}_{\mathrm{dr}}$. 


$$
\begin{aligned}
& \sum F_{y}=0, \quad \quad \mathrm{~N}_{\mathrm{df}}+\mathrm{N}_{\mathrm{dr}}=\mathrm{W} \\
& \sum F_{x}=0, \mathrm{~F}_{\mathrm{ps}}=\mathrm{U} *\left(\mathrm{~N}_{\mathrm{df}}+\mathrm{N}_{\mathrm{dr}}\right) \\
& \mathbf{F}_{\mathrm{ps}}=\mathrm{U} * \mathrm{~W}=0.6 * 400 * 9.8=\mathbf{2 3 5 2} \mathbf{N} \\
& \Delta \mathbf{W}=(2352 * 0.485) / 1.32=\mathbf{8 6 4 . 1 8 1} \mathbf{N} \\
& \mathbf{N}_{\text {df }}=\mathrm{N}_{\mathrm{sf}}+\Delta \mathrm{W}=1098.788+864.181=1962.969 \mathrm{~N} \\
& \mathbf{N}_{\mathrm{dr}}=\mathrm{N}_{\mathrm{sr}}-\Delta \mathrm{W}=2821.212-864.181=\mathbf{1 9 5 7 . 0 3 1} \mathbf{N}
\end{aligned}
$$

Now that we have the final values of the Normal Reactions at the time of braking the force acting on the front and rear tyres due to friction can be calculated-

Ffront $=0.6 * 1962.969=1177.7814 \mathrm{~N}$

Frear $=0.6^{*} 1957.031=1174.218 \mathrm{~N}$

Torque due to these forces-

$\boldsymbol{\tau} \mathbf{f}=$ Ffront $* \mathrm{R}_{\mathrm{f}}=1177.781 * 0.2667=\mathbf{3 1 4 . 1 1 4 N m}$

$\boldsymbol{\tau} \mathbf{r}=$ Frear $* \mathrm{R}_{\mathrm{r}}=1174.218 * 0.305=\mathbf{3 5 8 . 1 3 6 N m}$

\section{Calculation of force transfer throughout the system-}

As discussed previously we assume our master cylinder should have an ideal pressure required for braking. Let this pressure be $\mathrm{P}$.

According To Pascal's Law if an incompressible system is applied with pressure $\mathrm{P}$ it will pass down in all the directions with the same value of pressure. Thus $\mathrm{P}$ pressure will be experienced by the Caliper Piston's Both front and rear.

For simplicity we assume to have only one front wheel and only one rear wheel. We'll reduce the required Torque also by a factor of 2 .

$\mathrm{FCf}=$ Force applied by the front Caliper Piston

$\mathrm{FCr}=$ Force applied by the rear Caliper Piston

$\mathrm{FCf}=\mathrm{P} * \pi\left(\mathrm{DCf}^{\wedge} 2\right) / 4=\mathrm{P} \pi(0.03 * 0.03) / 4=\mathrm{P}^{*}(7.068 \mathrm{e}-4)$

$\mathrm{FCr}=\mathrm{P} * \pi\left(\mathrm{DCr}^{\wedge} 2\right) / 4=\mathrm{P} \pi(0.03 * 0.03) / 4=\mathrm{P} *(7.068 \mathrm{e}-4)$

F Clamp front $=2 * \mathrm{FCf}=\mathbf{P}(\mathbf{1 4 . 1 3 7 e - 4 )}$

F Clamp rear $=2 * \mathrm{FCr}=\mathbf{P}(\mathbf{1 4 . 1 3 7 e - 4 )}$

Clamping force will cause a friction generation between the pads and the discs. We have 0.4 as the frictional coefficient between the pads and the disc. We have already selected the radius of both the discs. We now need to choose an effective disc radius for both the front and rear discs.

This is calculated by considering that the max effect of the pads will be at the center of the caliper piston which is having a radius of $15 \mathrm{~mm}$ we also take $5 \mathrm{~mm}$ as spacing, Thus Reff front $=\mathrm{R}$ front $-20=70-20=50 \mathrm{~mm}$

Reff rear $=R$ rear $-20=95-20=75 \mathrm{~mm}$

$\mathrm{F}$ frictional front $=\mathrm{F}$ clamp front $* 0.4=\mathrm{P}(5.654 \mathrm{e}-4)$

F frictional rear $=F$ clamp rear $* 0.4=\mathrm{P}(5.654 \mathrm{e}-4)$

Frictional Torque generated $=$ Ffrictional front $*$ Reff front $=\mathbf{P}(2.87 \mathrm{e}-5)$

Frictional Torque generated $=$ Ffrictional rear $*$ Reff rear $=\mathbf{P}(4.24 \mathrm{e}-5)$

Previously we have calculated the values of the Torque that needs to be produced-

$\boldsymbol{\tau f}=$ Ffront $* \mathrm{Rf}=1177.781 * 0.2667=\mathbf{3 1 4 . 1 1 4 N m}$

$\boldsymbol{\tau} \mathbf{r}=$ Frear $* \mathrm{Rr}=1174.218 * 0.305=\mathbf{3 5 8 . 1 3 6 N m}$

Since we have considered half of the vehicle we reduce these values of torque by 2 before equating it with the frictional torque that is generated.

$\mathrm{P}(2.87 \mathrm{e}-5)=314.114 / 2$

$\mathbf{P}=5.47 \mathrm{MPa}$
$\mathrm{P}(4.24 \mathrm{e}-5)=358.136 / 2$

$\mathrm{P}=4.22 \mathrm{MPa}$

Thus, These are the required values of pressure in the master cylinder for locking respective wheels. 5.47 MPa is at least required pressure in the circuit for both the wheels to be locked simultaneously.

Thus for generating this pressure we will need to have an applied force on the plunger=

$\mathbf{F}$ req $=(5.47 \mathrm{e} 6) * \pi(0.01905 * 0.01905) / 4=\mathbf{1 5 5 9 . 0 7} \mathbf{~ N}$

Thus this is the required force on the Plunger of the Master Cylinder. Pedal Ratio is chosen as per the driver's comfort such that he may be able to apply this force without much effort. Let's assume that he applies a force of $225 \mathrm{~N}$ ideally hence we get a pedal ratio of $=1559 / 225=7: 1$

\section{BRAKE PEDAL DESIGN}

The brake pedal was made from scratch considering a balance in weight and strength. The design was catered towards ergonomics and driver comfort. The pedal was tested for working in such stressed conditions using ANSYS 19.2. The details of the pedal are given below-

Pedal Ratio - 7:1

Material - ASTM A36 Structural Steel

Weight - 210 gms (approx)

Manufacturing Techniques- Metal Hand Cutting

Metal Hand Grinding

Arc Welding

Drilling

Mesh Data- (Analysis type- Static Structural)

Mesh Size- $2 \mathrm{~mm}$

Mesh Type- Hex Dominant

Mesh Element Order- Quadratic

Number of Nodes- 28432

Number of Elements- 6107

The pedal was tested with an applied force of $225 \mathrm{~N}$ on the Pedal face, the hinge pivot was fixed while the master cylinder pivot was acted upon by a force of $1559 \mathrm{~N}$ representing the reaction force applied by the master cylinder as the driver pressed the brake pedal. Fig-3 shows all the boundary conditions applied.

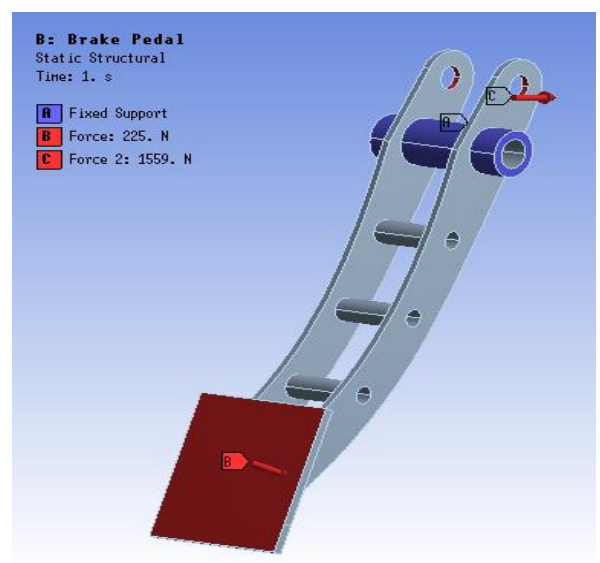

Fig -3: Applied Boundary Conditions

After setting up all the boundary conditions we ran the solver for finding out the following values

Maximum equivalent stress (Fig - 4) 
Maximum deformation (Fig - 5)

Minimum safety factor of our part (fig - 6)

We have taken a yield strength of 210MPa for the A36 Steel used for making the brake pedal.

The results are displayed as follows-

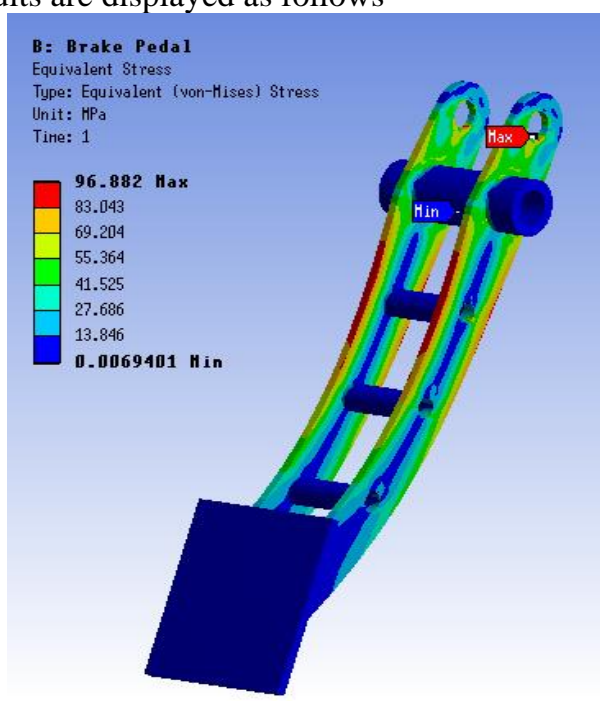

Fig - 4: Maximum Equivalent Stress(MPa)

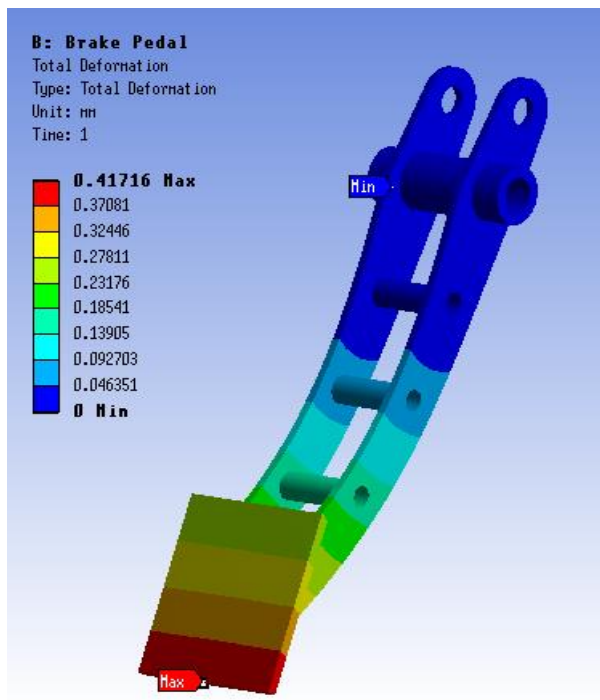

Fig - 5: Maximum Deformation(mm)

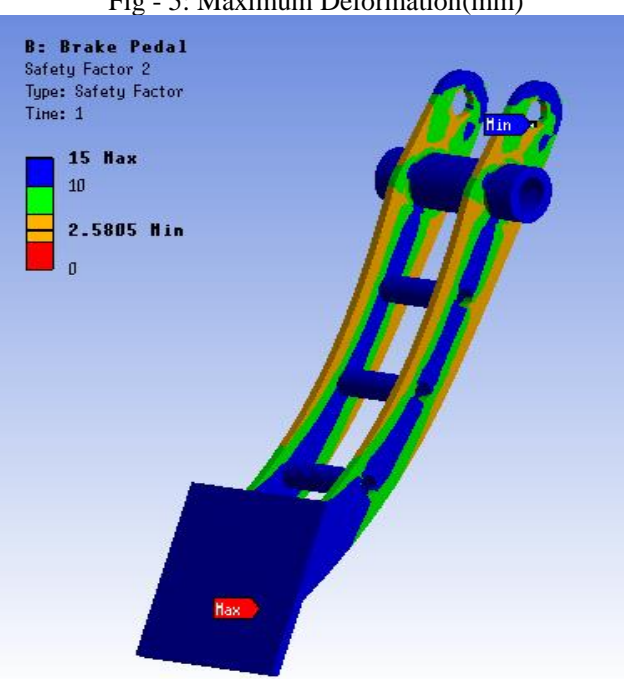

Hence we may conclude that our part is safe for 2.5 times the load for which it is meant to operate and this is safe for our use. The design incorporated using two plates and joining them together with hollow cylinders which also provides us with torsional strength while keeping the two plates balance the load among themselves.

\section{MASTER CYLINDER AND PEDAL MOUNTING}

The Master Cylinder and pedal are mounted on a common mounting that facilitated the brake application. The assembled setup of the brake pedal, master cylinder and the mounting is shown in the figure below-

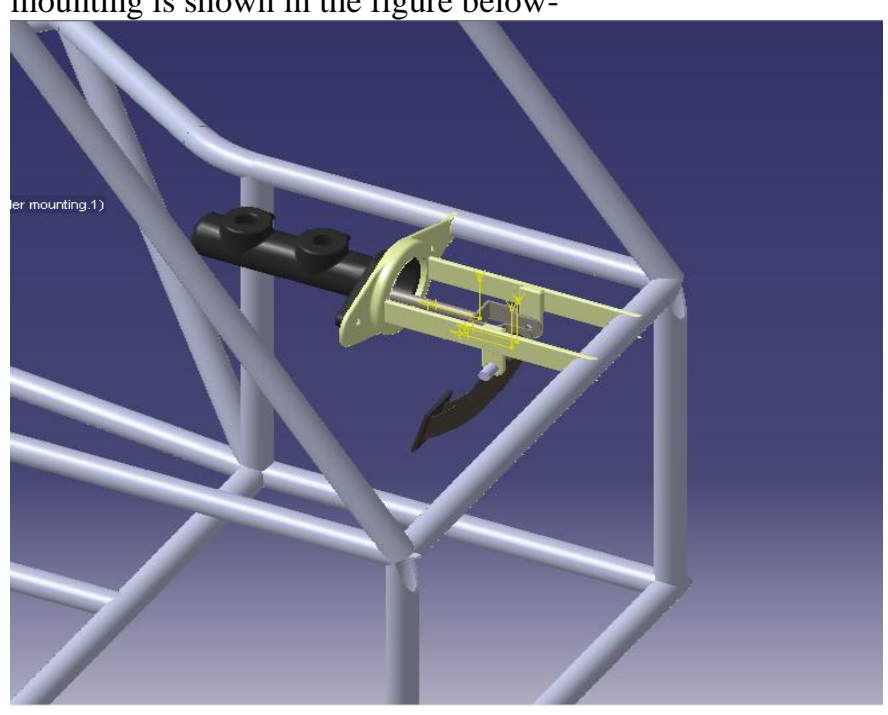

Fig - 7: Master Cylinder and Pedal Mounting

a) Using a common mounting for both the brake pedal and the master cylinder provided us with less weight and more functionality. The mounting is further analysed for structural integrity. A Fatigue analysis is also done to ensure the life of the part. The details of the mounting are given below-

Material - ASTM A36 Structural Steel

Weight - 930 gms (approx)

Manufacturing Techniques- Metal Hand Cutting

Metal Hand Grinding

Arc Welding

Drilling

Mesh Data- (Analysis type- Static Structural)

Mesh Size- $2 \mathrm{~mm}$

Mesh Type- Hex Dominant

Mesh Element Order- Quadratic

Number of Nodes- 130079

Number of Elements- 35600

Assumptions taken during the selection of loading conditions on the Master Cylinder mounting were-

1. Considered that the forces due to its own weight and the weight of the pedal/master cylinder were negligible.

2. The master cylinder is rigidly connected to the mounting.

Fig - 6: Safety Factor 
3. The forces acting on the plunger of the master cylinder are transferred to the body of the master cylinder.

4. Since the master cylinder body and the mounting are rigidly connected the mounting experiences the force on the faces that are bolted to the master cylinder, this force creates a moment that tries to bend the mounting.

The master cylinder is applied with these boundary conditions. The loading conditions are shown below in the following diagram-

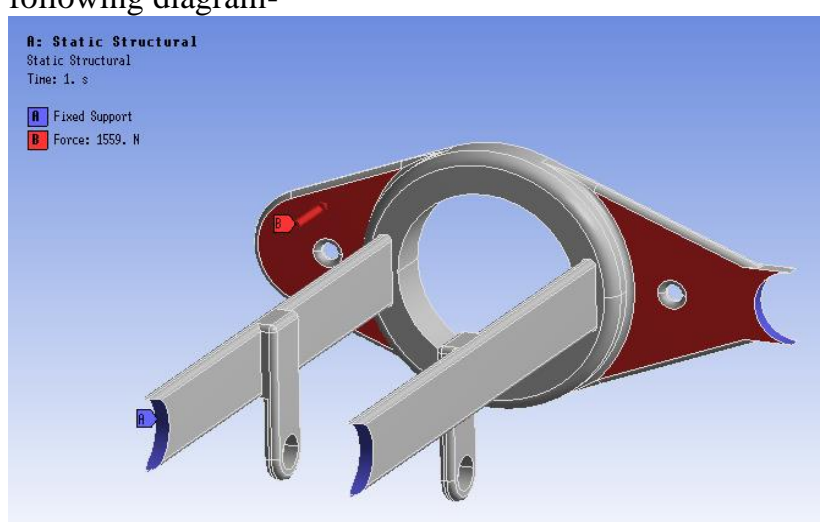

Fig - 8: Loading Conditions Mounting

The results are calculated by the solver for the following parameters-

Equivalent Stress (Fig-9)

Total Deformation (Fig - 10)

Safety Factor (Fig - 11)

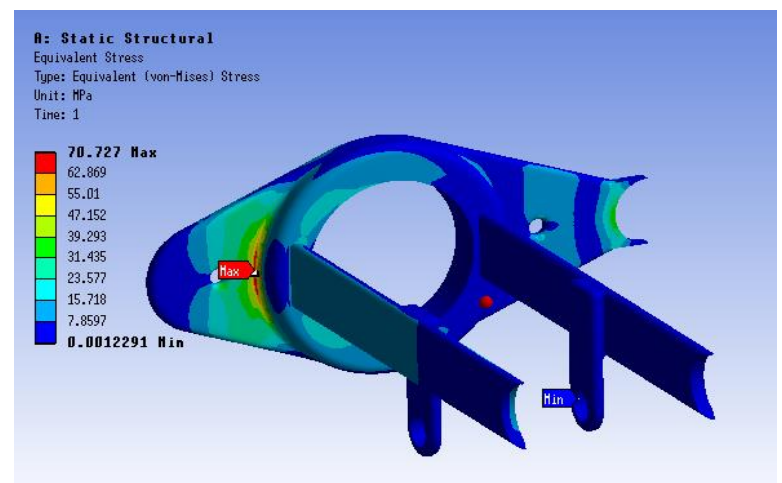

Fig - 9: Equivalent Stress in Mounting

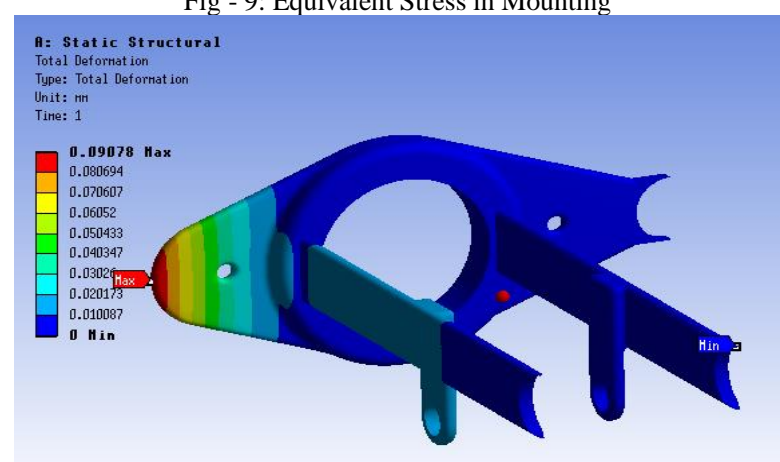

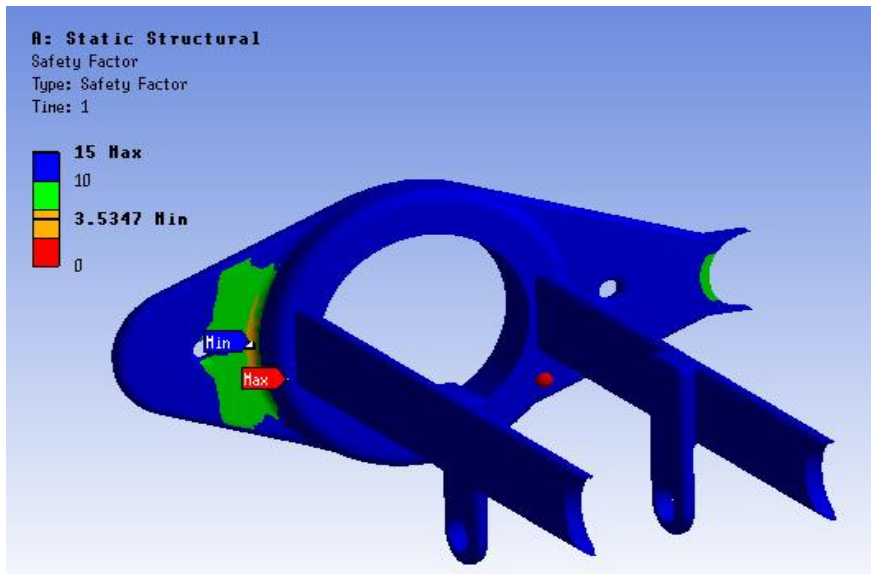

Fig - 13: Safety Factor of Mounting

Hence we may conclude that the part is safe for 3.5 times its normal loading conditions and will be sufficient for handling excessive stresses while being used.

We conclude that our overall pedal assembly and mounting weighs under $1.5 \mathrm{Kgs}$ and is capable of locking all four wheels when forces are applied during panic braking.

\section{BRAKE DISC DESIGN-}

As discussed previously we have 2 separate discs for the 2 working conditions the smaller disc was used in the front wheel rim that had smaller space compared whereas the larger disc was used in the rear axle. This was the inboard disc which was used in the rear axle.

The Forces experienced by the brake discs were previously calculated in terms of P. We'll substitute the value for P to get the exact force value. During our calculations we found out that the values of $\mathrm{P}$ comes different for the front Wheels and the rear Wheels. We chose the larger of the two values to ensure that both the wheels lock simultaneously. By doing this we are providing more pressure than required to the rear wheels.

$\mathrm{FCf}=\mathrm{P} * \pi\left(\mathrm{DCf}^{\wedge} 2\right) / 4=(5.47 \mathrm{e} 6) *(7.068 \mathrm{e}-4)=3866.19 \mathrm{~N}$

$\mathrm{FCr}=\mathrm{P} * \pi\left(\mathrm{DCr}^{\wedge} 2\right) / 4=(5.47 \mathrm{e} 6) *(7.068 \mathrm{e}-4)=3866.19 \mathrm{~N}$

Note that the $\mathrm{FCf} / \mathrm{FCr}$ is the force applied on one face of the disc the same force will be applied on the other side too thus clamping the disc.

Moments experienced by both the discs due to the frictional forces

Frictional Torque front $=\mathrm{P}(2.87 \mathrm{e}-5)=\mathbf{1 5 6 . 7 8 9} \mathrm{Nm}$

Frictional Torque rear $=\mathrm{P}(4.24 \mathrm{e}-5)=\mathbf{2 3 1 . 9 2 8 N m}$

Details about the discs-

a. Front Disc

Material - Stainless Steel 32

Weight - 200 gms (approx)

Manufacturing Techniques- Water Jet metal Cutting

b. Rear Disc

Material - Stainless Steel 321

Weight - 290 gms (approx)

Manufacturing Techniques- Water Jet metal Cutting

Fig - 10: Total Deformation in Mounting 


\section{A. $\quad$ Static Structural Analysis}

For the static structural analysis the mesh used was Hex Dominant to maximize the accuracy in result. The following are the details of the mesh designed-

a. Front Disc

Mesh Size- 3mm

Mesh Type- Hex Dominant

Mesh Element Order- Quadratic

Number of Nodes- 18049

Number of Elements- 3856

For the static structural analysis of both the discs the boundary conditions used were the forces applied on the faces by the pads, the moment generated due to the resistive frictional forces while the centre hole was kept fixed. The magnitude of all these forces are calculated above.

The Boundary conditions for structural analysis of front disc are shown in the figure 14.

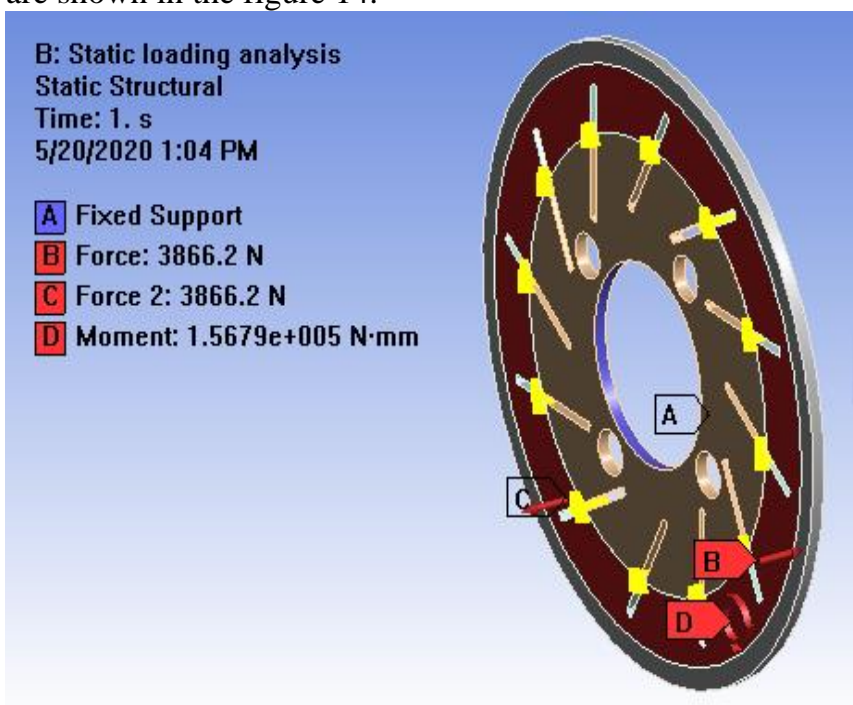

Fig - 14: Front Disc Boundary Conditions

Under these boundary conditions we calculated values for Total deformation and Equivalent stresses developed in the body of the disc. The following figures show changes under these loading conditions-

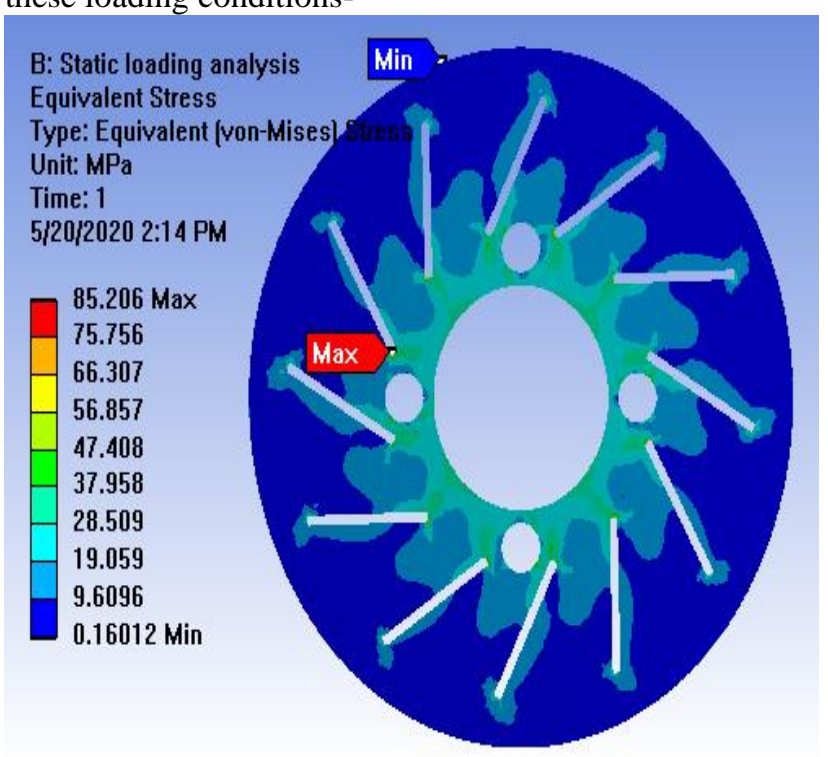

Fig - 15: Front Disc Eq. Stress

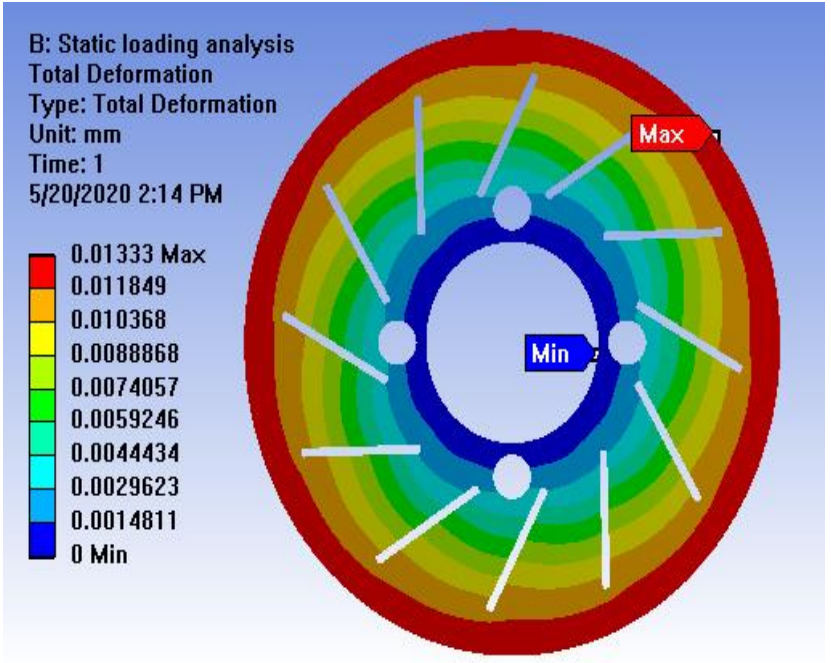

Fig - 16: Front Disc Total Deformation

As visible clearly the disc reaches a max stress of $85.206 \mathrm{Mpa}$. This is under working conditions as the yield stress of stainless steel is 2.5 times this value. Thus the disc is structurally strong for our working conditions.

b. Brake Disc

Mesh Size- 3mm

Mesh Type- Hex Dominant

Mesh Element Order- Quadratic

Number of Nodes-33601

Number of Elements- 7816

As clearly visible in the model(Fig-19) there are more slots and holes in the area where the pads will clamp the disc(the yellow area). This is done to maximize the area for better heat dissipation.

The Boundary conditions for structural analysis of rear disc are shown in figure 20.

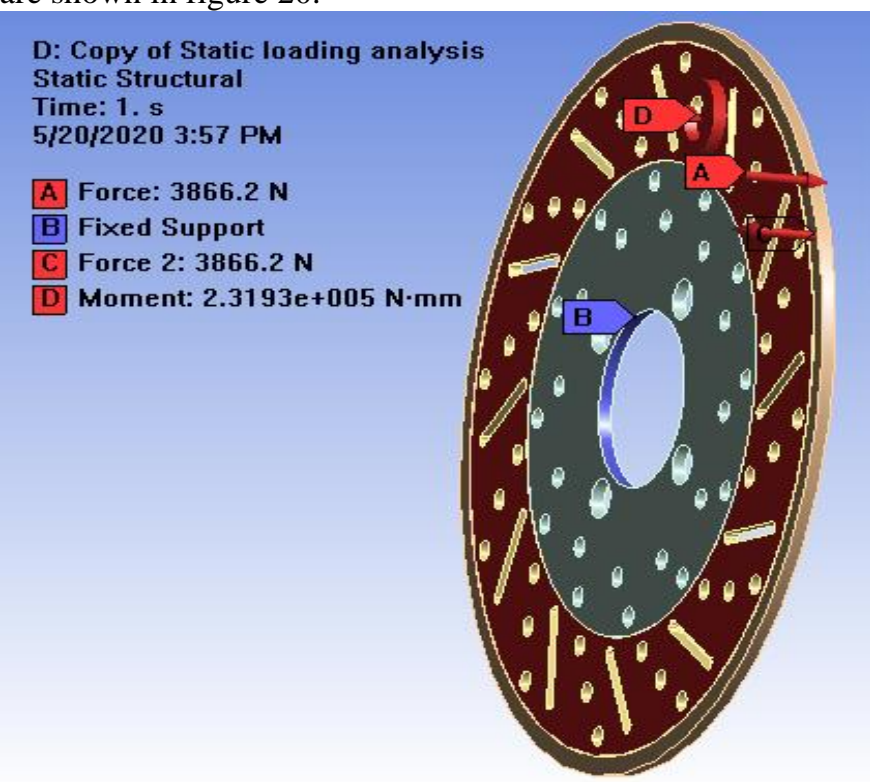

Fig- 17: Rear Disc Boundary Conditions

Under these boundary conditions we calculated values for Total deformation and Equivalent stresses developed in the body of the disc. The following figures show changes under these loading conditions 


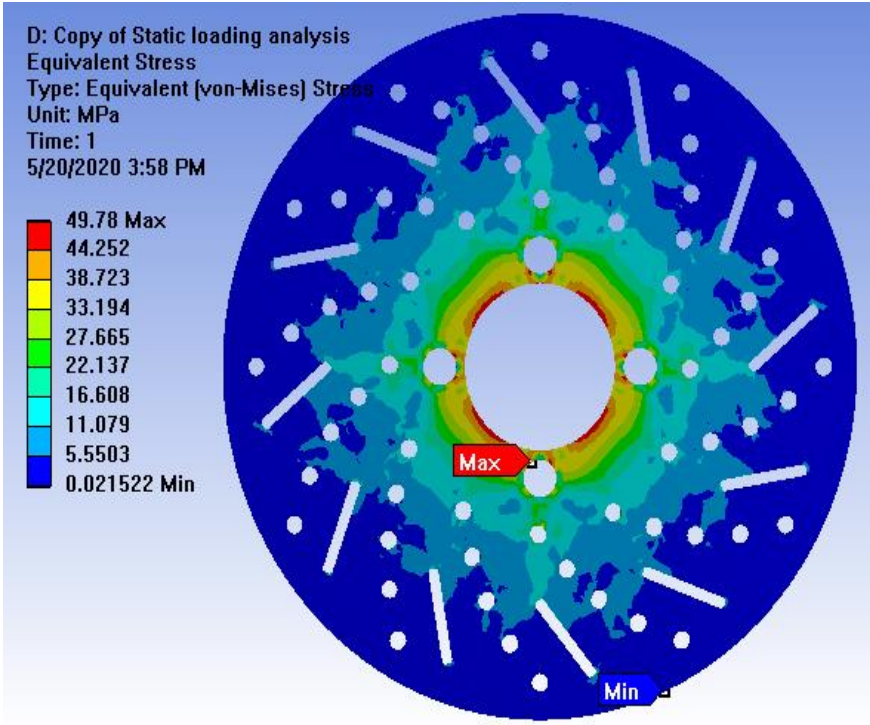

Fig -18: Rear Disc Eq. Stress

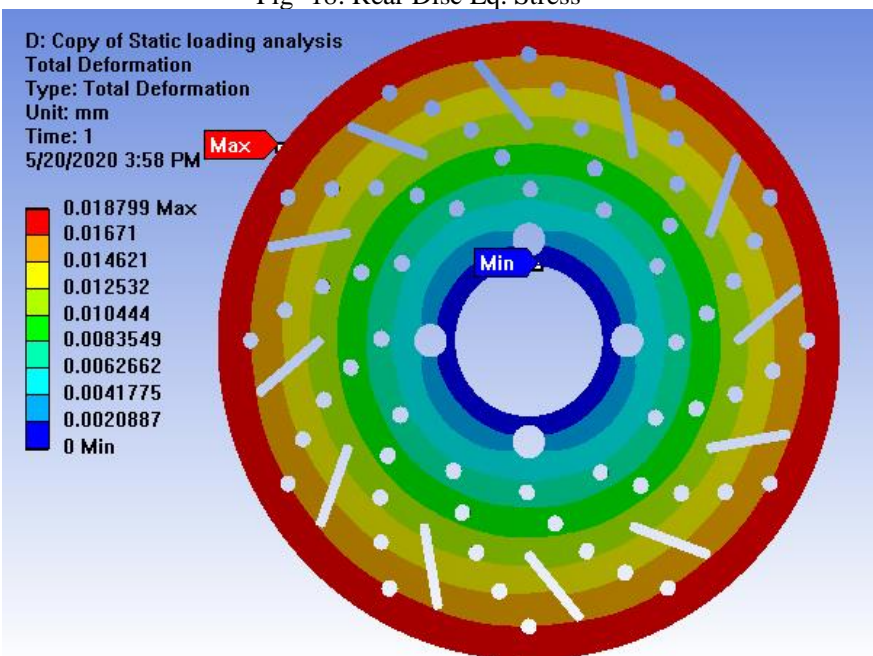

Fig - 19: Rear Disc Total Deformation

\section{ACKNOWLEDGMENT}

The work done in this paper was the original work of the author. I would like to thank my mentors, seniors and professors that inspired me to constantly work and achieve proficiency. I would also like to thank all the members of TEAM IGNITRR and TEAM UNITED RACING who have helped me throughout by clearing all my doubts and queries.

\section{REFERENCES}

[1] Brake Handbook, Fred Puhn

[2] Thermal analysis of a solid brake disc, Ali Belhocine*, Mostefa Bouchetara, Applied Thermal Engineering, Volume 32, Elsevier, 2011

[3] Aman Sharma1, Prakhar Amrute, Suryakant Singh Thakur, Jatin Shrivastav: Design, analysis and fabrication of braking system with rear inboard brakes in baja atv, IRJET, 2018

[4] Kush Soni, Gaurang Vara, Ishit Sheth, Harshil Patel: Design and Analysis of Braking System for ISIE ESVC, IJAER, 2018

[5] Swapnil R. Abhang , D.P.Bhaskar: Design and Analysis of Disc Brake, IJETT, 2014

[6] Priyesh Jain, Hitesh Garani,Analysis And Assessment Of Dual Brake Circuits, IJMET, 2016

[7] Design and Analysis of Disc Plate of an All Terrain Vehicle, IJSDR

[8] Finite Element analysis theory and applications with ANSYS, Saeed Moaveni 